\title{
The Reduction Of Administrative Burdens And Its Impact On The Competitiveness Of Business
}

Stanka Setnikar Cankar, Ph.D., University of Ljubljana, Slovenia

Veronika Petkovšek, University of Ljubljana, Slovenia

\begin{abstract}
This paper focuses on the reduction of administrative burdens in Slovenia and how these actions can influence the competitiveness of business. The aim of the paper is to study and analyse the current situation in the field of Slovenian regulations and the disadvantages of the regulations for businesses, to study the possibilities for reducing administrative burdens in Slovenia and to analyse the influence of cross-border cooperation on the reduction of administrative burdens.

The paper first describes the regulations and their impact on the competitiveness of business using the data from different international studies that include business environment and competitiveness and by using the results of the research carried out in Slovenia on defining the most burdensome areas of legislation. The paper continues by discussing the reduction of administrative burdens, where the Programme for the Elimination of Administrative Barriers and the Reduction of Administrative Burdens by 25\% by 2012 is introduced. The third part of the paper describes the possible connection between the reduction of administrative burdens and cross-border cooperation by introducing the results of a cross-national empirical survey of the current situation and future potentials of cross-border cooperation in the Alps-Adriatic region. At the end, the paper gives some conclusions on the reduction of administrative burdens and the resulting impact on business competitiveness in Slovenia.
\end{abstract}

Keywords: The Reduction of Administrative Burdens; Business Competitiveness; Regulation; Cross-Border Cooperation

\section{INTRODUCTION}

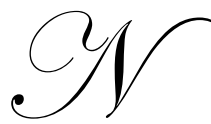

ational competitiveness is one of the key factors in the global economic race. The economic success of the modern economy depends heavily on the role, position and relationship of business with other countries in the world. Checking the level of national competition helps to raise the profile of the economy and its competitive position. The government and public administration has a significant impact on the competitiveness of the economy. This role is seen primarily in the areas of education, science and technology. The state's ability to develop a superior educational system and its increasing workforce skills, management and public administration, is a key step in increasing global competitiveness. The key role of the state in competitiveness is to strengthen the environment in which businesses operate.

The increased competitiveness of the economy may thus be achieved through higher quality public administration. One possibility for this is to improve the administrative processes through cross-border cooperation. Regulations set out by the public sector are affecting the competitiveness of businesses and the economy as a whole. For this reason, the improvement of administrative procedures can positively contribute to the competitiveness of the economy. Higher quality public administration can therefore be increased through cross-border cooperation, particularly with the transfer of good practices from neighbouring countries, by eliminating administrative barriers and by amendments to the legislation. 


\section{REGULATIONS AND THEIR IMPACT ON THE COMPETITIVENESS OF BUSINESS}

A good regulatory framework is one of the cornerstones of a competitive economy, as it supports the implementation of procedures by which companies and individuals meet daily. In addition to regular business, the legislation is also essential for new investments and business development.

According to the World Bank study published in the publication Doing Business 2010, which refers to the analysis of the business and regulatory environment, Slovenia is ranked at $53^{\text {rd }}$ among 183 countries. Based on analysis, it can be reasonably assumed that the Slovenian legislation is still bureaucratic, complicated and does not allow the economy a greater impulsion. In addition to the activities already carried out, there are still additional necessary activities and efforts on the part of the Government to improve the situation. Compared to 2009, Slovenia improved her position by 5 places in 2010, primarily due to the elimination of administrative barriers in the field of business start-ups ( $26^{\text {th }}$ place) and the more efficient implementation of contracts $\left(60^{\text {th }}\right.$ place). For a few years now, Slovenia has taken the worst place in the field of the recruitment process $\left(162^{\text {th }}\right.$ place $)$ and in the field of the registration or transfer of ownership $\left(108^{\text {th }}\right.$ place $)$. One of the worse areas is also the area of building permits, where Slovenia occupies the $59^{\text {th }}$ place (Action Plan to Reduce Procedures and Eliminate Administrative Burdens, 2010, p. 2).

Table 1: Slovenia's ranking in doing business 2009, 2010

\begin{tabular}{|l|r|r|}
\hline & 2009 & 2010 \\
\hline Ease of doing busines & 58 & 53 \\
\hline Starting a business & 42 & 26 \\
\hline Dealing with construction permits & 69 & 59 \\
\hline Employing workers & 159 & 162 \\
\hline Registering property & 106 & 108 \\
\hline Getting credit & 84 & 87 \\
\hline Protecting investors & 19 & 20 \\
\hline Paying taxes & 78 & 84 \\
\hline Trading across borders & 82 & 84 \\
\hline Enforcing contracts & 80 & 60 \\
\hline Closing a business & 40 & 40 \\
\hline
\end{tabular}

Source: Doing Business 2010: Slovenia, p. 2

*183 countries included in international comparison

Analysis from the perspective of the user focus on small and medium-sized businesses, primarily on the costs and time required for procedures necessary to: start-up a new business, obtain permits for construction, employment, property registration, access to debt financing, protecting investors, paying taxes, international business, the implementation of contracts and the termination of business operations. The complexity and length of administrative proceedings in these areas has very important implications for the competitiveness of the economy, domestic and foreign investment and thus economic development (Action Plan to Reduce Procedures and Eliminate Administrative Burdens, 2010, p. 2).

Beside the World Bank's study, the Institute for Management Development in the World Competitiveness Yearbook 2010 study analyses four areas of competitiveness and one of them is government efficiency, where Slovenia takes the $53^{\text {th }}$ ranking out of 58 countries analysed in 2010 . The ranking got worse by 15 places in comparison with the ranking in 2009 ( $38^{\text {th }}$ ranking). Going by sub factors of government efficiency in 2010, Slovenia was best ranked in the field of public finance $\left(44^{\text {th }}\right.$ place), followed by the institutional framework and societal framework $\left(46^{\text {th }}\right.$ place), business legislation $\left(49^{\text {th }}\right.$ place $)$ and the worst place went to fiscal policy $\left(53^{\text {rd }}\right.$ place). The competitive advantages for Slovenian government efficiency in 2010 were: start-up procedures and startup days for businesses, tariff barriers, exchange rate stability and corporate tax rate on profit. But improvements are still needed in the labour regulations, real personal taxes, unemployment legislation, foreign currency reserves and labour market flexibility (IMD World Competitiveness Yearbook 2010, 2010, p. 248). 
Also, the World Economic Forum in The Global Competitiveness Report 2010-2011 analyses different fields of competitiveness, one of them being institutions. Institutions are determined by a legal and administrative framework, within which individuals, businesses and governments operate in order to generate income and wealth in the economy. The quality of institutions has a major impact on competitiveness and economic growth as it affects investment decisions and the organization of production. The role of public institutions has significant weight. Here we can include property rights, government effectiveness, ethics, corruption and security (The Global Competitiveness Report 2010-2011, 2010, p. 4-5). In 2010, Slovenia was placed in the $50^{\text {th }}$ place in the field of institutions out of the 139 countries analysed. Institutions in Slovenia in 2010 were ranked the fourth worst from all twelve fields of competitiveness studied. In the field of institutions, the best ranked indicators in Slovenia were: the business costs of terrorism, crime and violence, the transparency of government policies, the protection of investors, irregular payments and bribes, the protection of intellectual property rights and organized crime. The worst ranked were: protection of the interests of minority shareholders, the effectiveness of management boards, the efficiency of the legislative framework for disputes and promotion rules. The most problematic factors for doing business in 2010 were access to financing, inefficient government bureaucracy, restrictive labour regulations, tax rates and tax laws (The Global Competitiveness Report 2010-2011, 2010, p. 300-301).

According to the OECD, the quality of the Slovenian business environment will largely depend on successful innovation policies. A key challenge in this optimization is cooperation and contacts between the research community, the business sector and the state. On the other hand, the European Commission believes that we need better and clearer organization of a supportive environment for entrepreneurship. Micro, small and medium-sized businesses need new solutions for financing growth and development and to promote entrepreneurship and innovation. Slovenia has recently improved the business environment for micro, small and medium-sized enterprises with activities to promote their activities, with the simplification of administrative procedures, by introducing a business register online for registering a business, by reducing time, by lowering the costs for momentum businesses and encouraging growth and innovation projects of micro, small and medium-sized enterprises. Even during the economic recovery from the effects of the global economic crisis, actions to support the environment for businesses are given great attention. The program of actions is based on four basic pillars: the promotion of entrepreneurship and a business-friendly environment, knowledge of the economy, development and innovation in the economy and promoting small and medium-sized enterprises through equity and debt financing. Through these actions, Slovenia would like to improve the entrepreneurial culture to create an effective and fully supportive environment, to ensure adequate and complete infrastructure, increase the investment in development, improve the integration of economies through science, ensure the transition of highly skilled human resources in the economy, create an effective environment for development and innovation and ensure favourable financial resources (Radić, 2010, p. 4-5).

Figure 1: The most burdensome areas of legislation for the private and public sectors in Slovenia

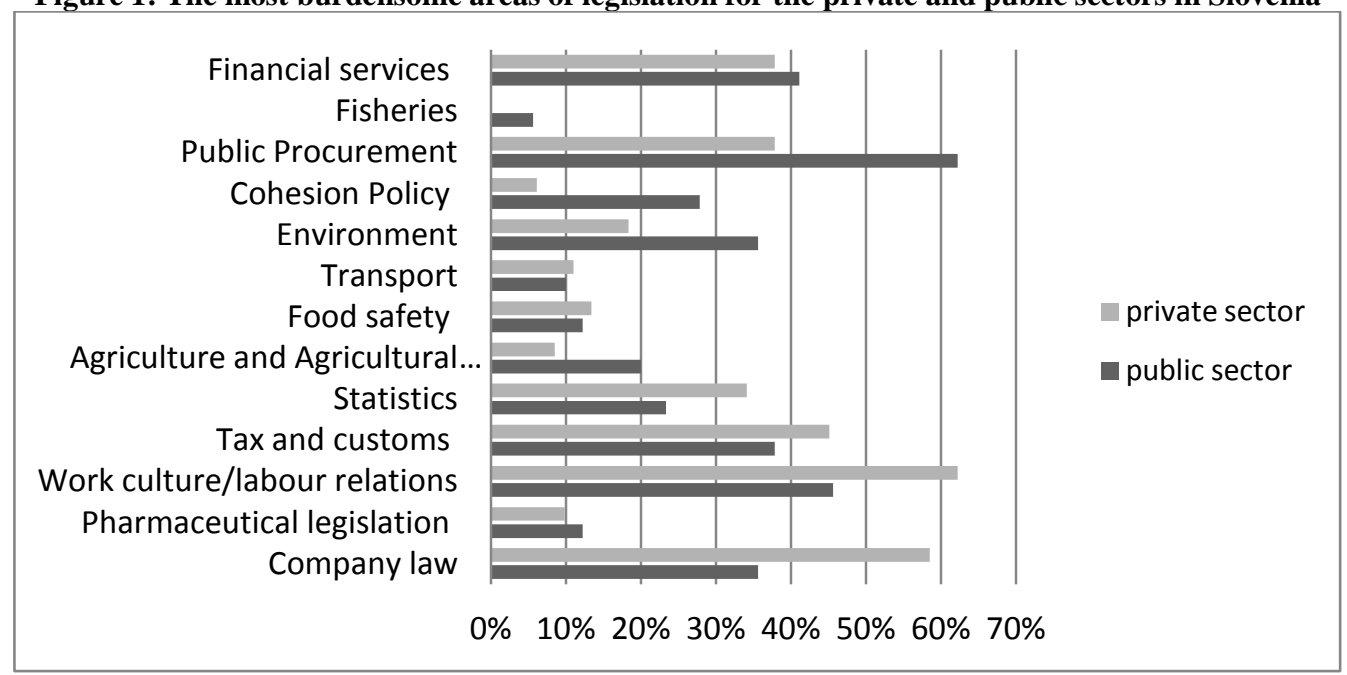

Source: Milavec \& Klun, 2011, p. 18 
In 2010 in Slovenia, research was carried out on the familiarity with reducing administrative burden measures and defining the areas of legislation where the greatest administrative burden for the private and public sector is seen. The results show that the majority of respondents in the private and public sector considers that the existing legislation represents a burden to their businesses or work. Thirteen priority regulatory areas were defined as the most burdensome. Employment relations is the most critical area according to the private sector, as $62.2 \%$ of all private sector respondents gave that response. The second critical area for the private sector (58.5\% responses) is company law and annual financial statements. Employment law is also ranked highly by the public sector respondents (45.6\% responses), but the most burdensome area for the public sector is public procurement $(62.2 \%$ responses) (Milavec \& Klun, 2011, p. 13, 15, 17-18).

The research also verified whether the private and public sectors are familiar with reducing the administrative costs of legislation. The reduction of administrative costs was only reported by micro and small-sized businesses and sole traders. The respondents from the private and public sectors consider that costs are increasing due to continual regulatory amendments (67.1\% respondents from the private sector, $75.6 \%$ from the public sector). The second reason for the increasing costs was the excessive amount of regulation $(63.3 \%$ respondents from the private sector, $58.8 \%$ from the public sector). The subsequent reasons were regulatory complexity and lack of clarity in regulations (Milavec \& Klun, 2011, p. 15-16)

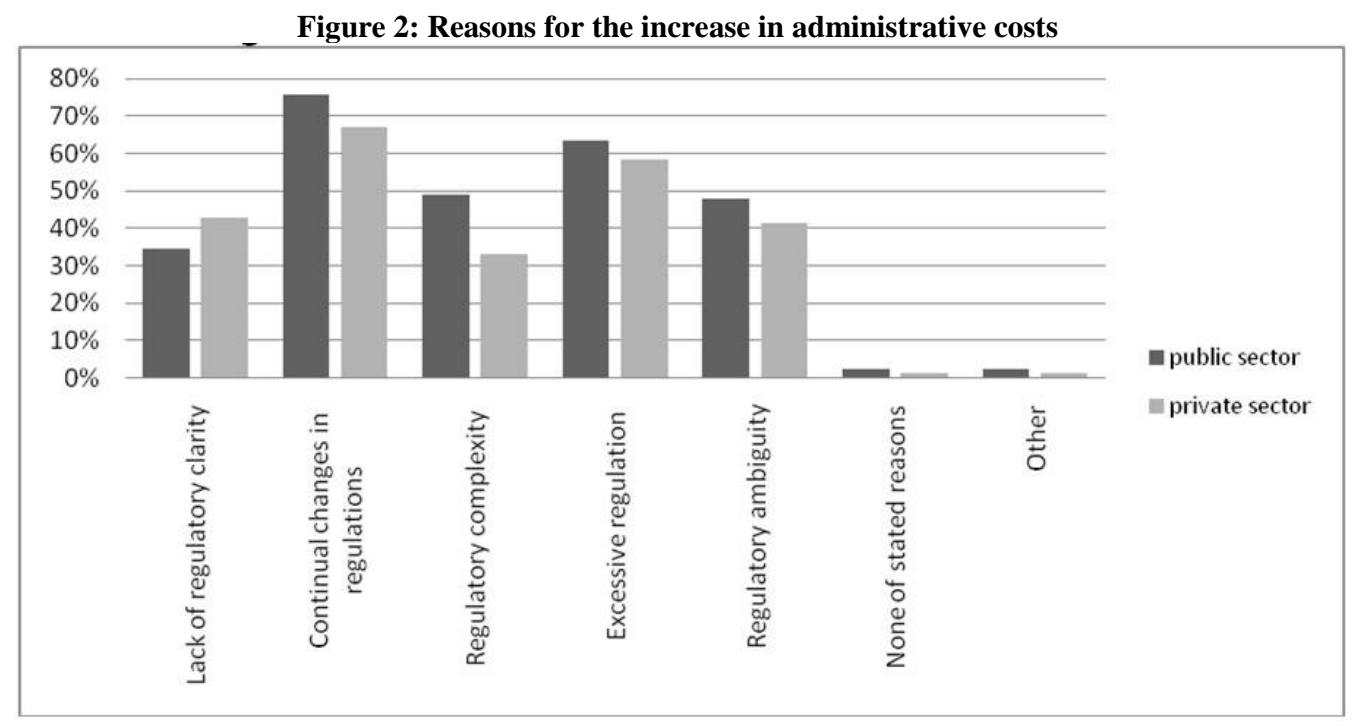

Source: Milavec \& Klun, 2011, p. 17

\section{THE REDUCTION OF ADMINISTRATIVE BURDENS}

The reduction of administrative burdens in the European Union represents an important action in ensuring the conditions for the effective functioning of the internal market and a tool that leads to achieving the medium-and long-term goals of the Lisbon strategy. To this end, the European Commission has prepared a program for reducing administrative burdens by $25 \%$ by 2012 . The overall reduction target of $25 \%$ is a common goal that can only be achieved on the basis of shared responsibility and the joint efforts of member states and European institutions. This program is not bound solely by the Commission but also by all member states, as administrative barriers also arise from national laws (The Elimination of Administrative Barriers on the Level of the European Union, 2011). With programs of actions for removing administrative burdens and simplifying administrative procedures, the country improves the situation of the national economy. Significant savings resulting from the reduction of administrative burdens is positively reflected in the competitiveness of the economy and domestic and foreign investment (The Elimination of Administrative Barriers and Reduction of Administrative Burdens, 2011).

In 2009, as a member state of EU, Slovenia adopted the Programme for the Elimination of Administrative Barriers and the Reduction of Administrative Burdens by $25 \%$ by 2012. The programme consists of two parts. The 
first part is Action Program for Reducing Administrative Burdens by 25\% by 2012 in the Republic of Slovenia. With this program, the government of Slovenia obliges all ministries towards the goal of minus $25 \%$, not only in the priority areas set by the European Commission but also in the other areas of work of individual ministries by 2012. The second part of the Program is the Program of Actions for the Elimination of Administrative Barriers (Programme for the Elimination of Administrative Barriers and the Reduction of Administrative Burdens by 25\% by 2012, 2009, p. 4).

The Action Program takes place in five stages. In the first stage, it is necessary to review the legislation in each field. In the second stage, it is necessary to measure the administrative costs of each field, in accordance with a common methodology. In the third stage we have to collect proposals for the simplification of legislation and in the fourth stage carry out amendments to the laws, on the basis of accepted proposals to reduce administrative burdens. In the final stage, the re-measurement of administrative costs and determining the effectiveness of changes is necessary to achieve the objective of the Action Program. The second stage, where we measure the administrative costs and burdens, is very important as the results of this measurement represent the basic factor for determining the efficiency of the changes with the Action program. The results of the measurement of the existing legislation are also very important in the procedure of Regulatory Impact Analysis (Programme for the Elimination of Administrative Barriers and the Reduction of Administrative Burdens by $25 \%$ by 2012, 2009, p. 8).

The Program of Actions for the Elimination of Administrative Barriers includes 41 concrete actions for elimination administrative barriers and concrete simplifications of procedures. The concrete actions were prepared on the basis of suggestions by residents of Slovenia, business subjects, chambers, ministries and others. In June 2010, the Slovenian Government adopted the Action Plan to Reduce Procedures and Eliminate Administrative Burdens. The Action Plan focuses on six priority areas of legislation: acquiring a building permit, employment law, the payment of taxes and contributions, ownership transfer, international transactions and the implementation of contracts. The reduction of administrative burdens and bureaucratic procedures improves business competitiveness. The EU focuses its activities on "cleaning-up" existing regulations and improving the procedures for new regulations. The action has taken part as a simplification of regulations and the reduction of administrative burdens. The aim was to de-bureaucratize legislation and reduce costs. It is vital for governments to focus on reducing administrative costs for businesses and individuals, which is vital for economic competitiveness and business competitiveness. The reduction of administrative burdens enables the use of funds for innovation, consolidates competitiveness and improves economic efficiency and effectiveness (Milavec \& Klun, 2011, p. 9-12).

Methods leading to simplifications within the elimination of administrative burdens include: 1 . the elimination, reduction, consolidation or improvement of legislation (elimination of unnecessary regulation, the use of alternatives to legislative regulation, aggregation and consolidation of the obligations or regulations, the simplification of terminology and reducing the complexity of regulations); 2 . simplifying processes within the legislative regulations (the elimination of unnecessary applications, forms and certificates, reducing the time needed for completing application forms and improving transparency, setting priorities, reducing the frequency of requests for information); 3. the exchange of information inside the government (getting information from the official records, the exchange of information within the state administration, establishing a business register system online, the development of standard definitions in the regulations); 4. the development of IT solutions and services (the development of online forms and applications, the development and production of interactive, intelligent forms, the establishment of a usable electronic business register system online through administrative web portals); 5 . providing better guidance and information (developing better and more accessible guidance on certain regulations, the use of simpler language, direct access to regulations via the internet) (Paths towards simplification within the elimination of administrative barriers, 2011).

\section{THE REDUCTION OF ADMINISTRATIVE BURDENS THROUGH CROSS-BORDER COOPERATION}

Cross-border cooperation comprises many levels of cooperation between regions of two bordering states. The goal of cooperation in border and cross-border regions is to develop cooperative structures, procedures and instruments that facilitate the removal of obstacles. The primary objective is to transcend borders and reduce their significance. Cross-border cooperation helps mitigate the disadvantages of borders, overcome the peripheral status of the border regions and improve the living conditions of the population (Medeiros 2010, p. 435-436). Therefore, cross-border cooperation helps overcome the structural disadvantages that were imposed mostly by their location on 
the edge of their country. The local players on either side of certain borders quickly realize that they are dependent on different systems but share common problems and interests. In order to overcome these problems, border regions try to join forces and find practical and fast solutions to their requirements (Ležaić 2010, p. 10).

Cross-border cooperation offers opportunities for social, economic and organizational development in the border regions. Cross-border cooperation makes the regions more competitive, sustainable and integrated (Cividin 2006, p. 9). Cross-border cooperation has become a crucial factor for the economic competitiveness of regions. The essential location factor in the context of cross-border cooperation is the development of institutional capacity and the ability to cooperate by political and administrative authorities (Roeber 2010, p. 1).

One of the possibilities to improve the business environment is higher quality public administration through better regulation. We can achieve that by cross-border cooperation, particularly with the transfer of good practices between neighbouring countries, by removing administrative barriers and by amendments to the legislation. In 2010, a cross-national empirical survey and analysis of the current situation and future potentials of cross-border cooperation in the Alps-Adriatic region was carried out. With the survey, we tried to determine the administrative barriers and the opportunities for reducing or eliminating them, to determine the current state of cross-border cooperation between Slovenia, Austria and Italy, further opportunities for cross-border cooperation in this area, the fields of cooperation and the advantages of cross-border cooperation for each country studied.

The results for Slovenia showed advantages in cross-border cooperation with Austria and Italy, both for the overall economy and for individual organizations. The advantages lie in economic development, business development, the transfer of knowledge, the transfer of experiences and good practices, better cooperation and integration, better opportunities for projects, better access to financial resources and simplifying administrative procedures. By stating simplifying administrative procedures, the respondents highlighted the search for common solutions in the field of legislation, simplifying administrative procedures in general and exchanging technical regulations. All the advantages mentioned above were very similar to Austria's and Italy's respondents, too. On the other side, the respondents also detected potential barriers to cross-border cooperation. Among the detected barriers were: the administrative system, legislation, changing the rules for businesses, complex funding systems and others. If we look more closely at the mentioned barriers, we can see from the figure below that $16 \%$ of all respondents consider complex funding system a major barrier to cross-border cooperation and also changing the rules for businesses (15\% of respondents). For $28 \%$ of the respondents, a complex funding system and for $26 \%$ of the respondents, changing the rules for businesses again represents a large barrier (under no. 2) but also legislation represents a big barrier for $22 \%$ of all respondents. The administrative system is a barrier (under no. 3) for $46 \%$ of respondents, followed by legislation (39\% of the responses) and changing the rules for businesses (35\% of the responses). $19 \%$ of the respondents consider the administrative system represents only a small barrier (under no. 4) and $13 \%$ that the administrative system represents no barrier at all. Also $17 \%$ of the respondents think that legislation represents only a small barrier and 6\% that are no barriers at all in the field of legislation for cross-border cooperation (Setnikar Cankar \& Petkovšek, 2010).

Figure 3: General conditions as a barrier to cross-border cooperation in Slovenia

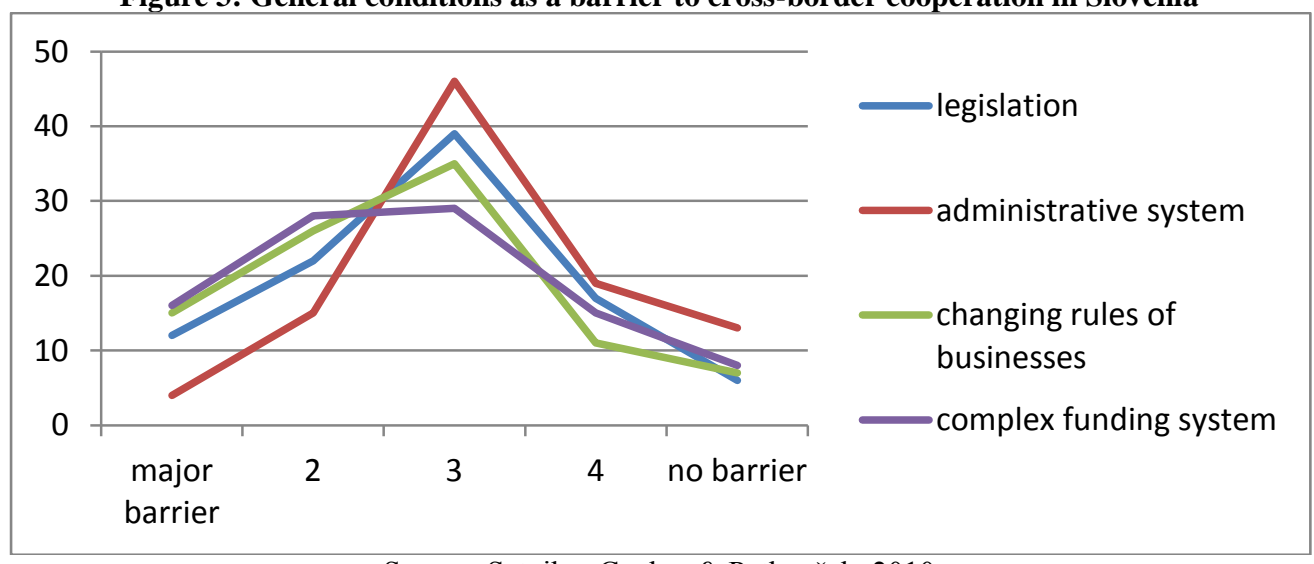

Source: Setnikar Cankar \& Petkovšek, 2010 
In order to improve cross-border cooperation between Slovenia, Austria and Italy and to reduce potential barriers to cross-border cooperation, the respondents from Slovenia suggested: simplifying and shortening administrative procedures, the harmonisation of laws on both sides of the border, improving and simplifying legislation, shortening the duration of the procedures, simplifying the paperwork in project implementation, easier reporting, to increase funding opportunities for cross-border projects, such as more possibilities for financing joint projects, provide free legal and administrative services for project leading, more direct incentives from the state; to increase the information on cross-border cooperation and to establish an agency that deals with issues of crossborder cooperation (Setnikar Cankar \& Petkovšek, 2010).

The survey also analyses the future potentials and perspectives of cross-border cooperation in the AlpsAdriatic region. The most important cooperation areas in Slovenia for future cross-border cooperation with Austria were tourism development and marketing in the first place, business in the second place and culture and environment and energy in the third and fourth places. For cross-border cooperation with Italy, Slovenia places tourism development and marketing in the first place and business in the second place again, like in Austria. In the third and fourth place, Slovenia places environment and energy and infrastructure and transport.

Table 2: Cooperation areas in Slovenia for future cross-border cooperation with Austria and Italy

\begin{tabular}{|l|l|l|}
\hline \multicolumn{1}{|c|}{ Rank } & \multicolumn{1}{|c|}{ Cooperation with Austria } & \multicolumn{1}{c|}{ Cooperation with Italy } \\
\hline 1. & tourism development and marketing & tourism development and marketing \\
\hline 2. & business & business \\
\hline 3. & culture & environment and energy \\
\hline 4. & environment and energy & infrastructure and transport \\
\hline
\end{tabular}

Source: Setnikar Cankar \& Petkovšek, 2010

Slovenia's future cooperation areas with Austria and Italy show that business cooperation is one of the most important fields for cross-border cooperation in the future. For that reason, the reduction of administrative burdens and the elimination of administrative barriers is essential from this point of view as well.

The results of the survey show that cross-border cooperation can be a way to improve public administration, especially influencing the reduction of administrative burdens in the sense of simplifying administrative procedures and legislation. By detecting potential barriers in countries on both sides of the border, cross-border cooperation can bring common solutions to eliminate or reduce those barriers. The transfer of knowledge, experiences and good practices through cross-border cooperation is a very important factor that can improve the quality of public administration and consecutively improve the regulations in each neighbouring country. A good practice of simplifying administrative procedures or legislation in one country can, by exchanging knowledge and experiences through cross-border cooperation, quickly become a solution for the common problem in the other neighbouring country. The successful reduction of bureaucratic procedures and administrative barriers improves business competitiveness and the competitiveness of the economy. Therefore, cross-border cooperation, especially in the field of public administration, should become more frequent.

\section{CONCLUSION}

Actions for eliminating administrative barriers and reducing administrative burdens are essential to improve the situation of the national economy. The European Commission prepared a program for reducing administrative burdens by $25 \%$ by 2012 , which was also adopted by the Slovenian government. Slovenian legislation is still bureaucratic complicated and does not allow the economy a greater impulsion. Slovenia has recently improved the business environment for micro, small and medium-sized enterprises with activities to promote their activities, with the simplification of administrative procedures, by introducing a business register online for registering a business, by reducing time, by lowering costs for momentum businesses and encouraging the growth and innovation projects of micro, small and medium-sized enterprises. However, on the basis of results of various international studies and analyses, which also include the business environment and competitiveness, Slovenia still has to improve the situation for businesses. Improvements should be made in the field of the recruitment process, the registration or transfer of ownership, labour regulations, real personal taxes, unemployment 
legislation, legislative framework for disputes and the promotion rules and many other fields of regulation.

The results of the research on the familiarity with reducing administrative burden measures and defining the areas of legislation where the greatest administrative burden for the private and public sector is seen show us that the most critical area according to the private sector are employment regulations, followed by company law and the annual financial statement. The results also show that administrative costs are increasing due to continual regulatory amendments, an excessive amount of regulation, regulatory complexity and lack of clarity in regulations. Therefore, Slovenia took the right step in 2009 when it adopted the Programme for the Elimination of Administrative Barriers and the Reduction of Administrative Burdens by $25 \%$ by 2012, which consists of two parts. The first part is the Action Program for Reducing Administrative Burdens by 25\% in the Period until 2012 in the Republic of Slovenia and the second part of the Program is the Program of Actions for the Elimination of Administrative Barriers. In 2010 the Slovenian Government adopted the Action Plan to Reduce Procedures and Eliminate Administrative Burdens, which focuses on six priority areas of legislation: acquiring a building permit, employment law, the payment of taxes and contributions, ownership transfer, international transactions and the implementation of contracts.

The business environment can therefore be improved by higher quality public administration through better regulation. Among other things, we can achieve this by cross-border cooperation, particularly with the transfer of good practices between neighbouring countries, by removing administrative barriers and by amendments to the legislation. In 2010, a cross-national empirical survey and analysis of the current situation and the future potentials of cross-border cooperation in the Alps-Adriatic region was carried out. The results show that among the advantages of cross-border cooperation, the respondents highlighted the simplification of administrative procedures by searching for common solutions in the field of legislation, simplifying administrative procedures in general and exchanging technical regulations. As well as the advantages, the respondents also detected potential barriers to cross-border cooperation, including the administrative system, legislation, changing the rules for businesses and complex funding systems. In order to improve cross-border cooperation between Slovenia, Austria and Italy and to reduce potential barriers to cross-border cooperation, the respondents from Slovenia suggested simplifying and shortening administrative procedures, increasing funding opportunities for cross-border projects, increasing the information on cross-border cooperation and to establish an agency for cross-border cooperation. The areas of future cooperation in Slovenia with Austria and Italy show that business cooperation is one of the most important fields for cross-border cooperation in the future and therefore the reduction of administrative burdens and the elimination of administrative barriers is vital from this perspective as well.

\section{AUTHOR INFORMATION}

Full Professor Stanka Setnikar-Cankar, Ph.D., graduated at the Faculty of Economics in 1976 and began working at the Administrative College. In 1993 she obtained the title of Doctor of Economics at the Faculty of Economics in Ljubljana. She is the author of many articles and books on public sector economics and editor-in-chief of the magazine "Administration". She is a member of the NISPACee Steering Committee, the Program Committee of annual conference of Public Administration in Slovenia, a member of IIASIA, EGPA, etc. She successfully heads and participates in various research projects, especially in field of Public Sector Reform (Tempus, Interreg, Leonardo da Vinci), Public Sector Reform in Health Care, effectiveness measurement in Public Administration and cross-border cooperation between Slovenia, Austria and Italy. In the 1996-2005 and 2009-2011 periods, she has carried out mandates as Dean of the Faculty of Administration. She is a member of the Strategic Council of the Republic of Slovenia for regionalization. E-mail: stanka.setnikar-cankar@ @u.uni-lj.si

Veronika Petkovšek graduated at the Faculty of Economics in Ljubljana in 2008. In 2008 she was employed at the Faculty of Administration as an assistant in the Department of Public Sector Economics. Her areas of research interest encompass Public Sector Economics in the field of changes to the healthcare system, public procurement and measuring the efficiency and effectiveness of the public sector. She also participates in the field of cross-border cooperation between Slovenia, Austria and Italy. E-mail: veronika.petkovsek@fu.uni-lj.si 


\section{REFERENCES}

1. Action Plan to Reduce Procedures and Eliminate Administrative Burdens (2010). Government of the Republic of Slovenia, Ljubljana.

2. Cividin, A. (2006) Irish Cross-border Cooperation: the Case of the Northwest Region, Mapping Frontiers, Plotting Pathways, Working Paper No. 14, Institute for British-Irish Studies.

3. Doing Business 2010: Slovenia (2010). The World Bank, Washington.

4. The Elimination of Administrative Barriers on the level of European Union (2011). Ministry of Public Administration, Ljubljana. Retrieved from http://www.mju.gov.si/si/delovna_podrocja/e_uprava_in_upravni_procesi/boljsi_predpisi_in_odprava_adm inistrativnih_ovir_oao/25_program vlade republike slovenije/.

5. The Elimination of Administrative Barriers and the Reduction of Administrative Burdens (2011). Government of the Republic of Slovenia, Ljubljana. Retrieved from http://www.vlada.si/si/teme_in_projekti/izhod_iz_krize/odprava_administrativnih_ovir/.

6. The Global Competitiveness Report 2010-2011 (2010). World Economic Forum, New York.

7. IMD World Competitiveness Yearbook 2010 (2010). Institute for Management Development, Lausanne.

8. Ležaić, K. (2010) Cross Border Cooperation as an Instrument of EU Regional Policy: Case Study: Croatia. Institut européen des hautes etudes internationals, Nice.

9. Medeiros Rocha, E. J. (2010) Old vs recent cross-border cooperation: Portugal - Spain and Norway Sweden, Area, 42(4), pp. 434-443.

10. Milavec, U. \& Klun, M. (2011). Familiarity with Measures to Reduce Administrative Burdens in the Public and Private Sector in Slovenia. Uprava, 11(1), 7-23.

11. Programme for Elimination of Administrative Barriers and Reduction of Administrative Burdens by 25\% by 2012 (2009). Government of the Republic of Slovenia, Ljubljana.

12. Radić, D. (2010). Note speech by mag. Darja Radić, the minister of Ministry of the economy of Republic of Slovenia. Consultations on Slovenian diplomacy. Brdo pri Kranju.

13. Roeber, J. (2010) Towards an Ever Closer Region? Explaining Administrative Cross-Border (Non-) Cooperation from the Vantage Point of Lake Constance, EGPA Study Group on Regional and Local Government, September 8-10, 2010, IEP Toulouse.

14. Setnikar Cankar, S., Petkovšek, V., (2010) Survey of Cross-border cooperation in the Alps-Adriatic region, Faculty of Public Administration, Ljubljana

15. Paths towards simplification within the elimination of administrative barriers (2011). Ministry of Public Administration, Ljubljana. Retrieved from http://www.mju.gov.si/si/delovna_podrocja/e_uprava_in_upravni_procesi/boljsi_predpisi_in_odprava_adm inistrativnih_ovir_oao/odprava_administrativnih_ovir/. 
NOTES 